\title{
Cyclic Hydrodynamic Pressure Induced Proliferation of Bladder Smooth Muscle Cells via Integrin $\alpha 5$ and FAK
}

\author{
T.-Q. WEI ${ }^{1,2^{*}}$, D.-Y. LUO ${ }^{1 *}$, L. CHEN ${ }^{1}$, T. WU ${ }^{1}$, K.-J. WANG ${ }^{1}$ \\ * These authors contributed equally to this work.
}

${ }^{1}$ Department of Urology, West China Hospital, Sichuan University, Chengdu, ${ }^{2}$ Department of Urology, Nanchong Central Hospital, The Second School of Clinical Medicine, The Affiliated Hospital of North Sichuan Medical College, Nanchong, Sichuan, P.R.C

Received January 4, 2013

Accepted September 10, 2013

On-line November 1, 2013

\begin{abstract}
Summary
According to previous studies, integrins play an important role in the mechanotransduction. The aim of this study was to examine the role of integrin subunits and its down-stream signaling molecules in the cyclic hydrodynamic pressure-induced proliferation of human bladder smooth muscle cells (HBSMCs) cultured in scaffolds. The HBSMCs cultured in scaffolds were subjected to four different levels of cyclic hydrodynamic pressure for 24 hours, which were controlled by a BOSE BioDynamic bioreactor. Flow cytometry was used to examine cell cycle distribution. Real-time RT-PCR and western blotting were used to examine the expression levels of integrin subunits and their downstream signaling molecules. Integrin a5 siRNA was applied to validate the role of integrin $a 5$ in cell proliferation. Here, we showed that cyclic hydrodynamic pressure promoted proliferation of HBSMCs. The cyclic hydrodynamic pressure also increased expression of integrin a5 and phosphorylation of FAK, the key mediator of integrin a5 signaling, but not that of integrin a1, a3, $a 4, a v, \beta 1$ and $\beta 3$. Moreover, inhibition of integrin a5 decreased the level of p-FAK and abolished proliferation of HBSMCs stimulated by cyclic hydrodynamic pressure. Taken together, we demonstrate for the first time that the integrin a5-FAK signaling pathway controls the proliferation of HBSMCs in response to cyclic hydrodynamic pressure.
\end{abstract}

\section{Key words}

Hydrodynamic pressure • Proliferation • Human bladder smooth muscle cells

\section{Corresponding author}

Kun-Jie Wang, Department of Urology, West China Hospital,
Sichuan University, Chengdu, Sichuan, P.R.C. Fax: 86-28-8542 2451. E-mail: wzwzlwww@qq.com

\section{Introduction}

Mechanical stimuli are the major regulatory factor of normal tissue morphology and function, and an important determinant factor for cell or tissue fate under physiological and pathological conditions (Kessler et al. 2001, Zhou et al. 2005). Particularly, smooth muscle (SM)-rich tissues, such as the bladder smooth muscle, are constantly exposed to mechanical stimuli arising from fluctuations in cyclical hydrodynamic pressure, strain and periodic stretching. Breakdown of force equilibrium within these tissues occur often as a result of obstructive diseases or pressure overload triggered by pathophysiological changes, such as hypertrophy, hyperplasia, and various degrees of fibrosis (Chang et al. 2009, Koitabashi et al. 2011, Zhang et al. 2004). In response to mechanical stimuli, smooth muscle cells have altered expression of cell surface molecules, such as integrins, which act locally to orchestrate wide molecular and cellular changes.

Integrins are heterodimers of associated subunits of $\alpha$ and $\beta$, which include $18 \alpha$ and $8 \beta$ subunits that can assemble into 24 different receptors with different binding properties and different tissue distribution (Barczyk et al. 2010, Hynes 2002). A lot of data showed that the mechanical signals transduced by integrinmediated signaling pathways, which modulate various cellular functions, including growth and proliferation, 
cytoskeletal organization and motility, ion channel function, gene and protein expression, and extracellular matrix production and autocrine secretion (Engers and Gabbert 2000, Gerthoffer and Gunst 2001, Hood and Cheresh 2002).

Activation of specific integrins has been documented in different cells upon exposure to various mechanical stimuli. For example, cyclic stretch upregulated $\alpha v \beta 3$ in mice and rat vascular smooth muscle cells (VSMCs) (Chen et al. 1999, Cheng et al. 2007), while cyclic strain induced an association of $\alpha 1 \beta 1$ in mice VSMCs (Pyle et al. 2008). Wilson showed that cyclic strain induced an association of both $\beta 3$ and $\alpha v \beta 5$ integrins in rat VSMCs (Wilson et al. 1995). The mechanisms of mechanotransduction involved in integrin signal pathway in the other cell types, such as VSMC and osteocyte, have been fully illustrated (Davis 2010, Jacobs et al. 2010, Shi and Tarbell 2011). However, the role of integrins in proliferation of human bladder smooth muscle cells (HBSMCs) is not well defined. In addition, most studies used bladder smooth muscle cells isolated from animals such as rat and rabbit to investigate cellular response to mechanical stimuli (Deng et al. 2007, Stover and Nagatomi 2007). It is necessary to validate these studies using human bladder smooth muscle cells.

In this study, we treated HBSMCs with cyclic hydrodynamic pressure, which is different from mechanical stretch and hydrostatic pressure. By analyzing the expression of integrins upon cyclic hydrodynamic pressure exposure, we identified integrin $\alpha 5$ as the key molecules that mediated the signaling pathway induced by cyclic hydrodynamic pressure in HBSMCs.

\section{Materials and Methods}

\section{Materials}

HBSMCs (ScienCell, USA, Cat.No.4310), polyvinyl alcohol based scaffolds (BOSE, BioDynamic, USA), the computer-controlled bioreactor (BOSE, BioDynamic, USA), EPICS ELITE ESP flow cytometer (Beckman Coulter, FL), RNAiso Plus reagent (TaKaRa, Dalian, China), iScript cDNA Synthesis Kit (Bio-Rad, USA), SYBR Premix EX Taq premix reagent (TaKaRa, Dalian, China) and Bio-Rad iQ5 machine, RIPA buffer (Beyotime, China), PVDF membranes (Millipore, USA), the GAPDH antibody, Phospho-FAK (Tyr397) antibody, FAK antibody and integrin $\alpha 5$ Antibody(Cell Signalling Technologies, CST, USA), Lipofectamine2000 reagent and scrambled siRAN (Invitrogen, USA).
Cell culture

HBSMCs were cultured in DMEM supplemented with $10 \%$ fetal bovine serum, penicillin $(100 \mathrm{U} / \mathrm{ml})$ and streptomycin $(100 \mu \mathrm{g} / \mathrm{ml})$ at $37^{\circ} \mathrm{C}$ in a humidified atmosphere of $95 \%$ air $/ 5 \% \mathrm{CO}_{2}$. Cells between generations 3 and 7 were studied.

\section{Cyclic hydrodynamic pressure}

HBSMCs were seeded onto polyvinyl alcohol based scaffolds (BOSE, BioDynamic, USA) contained in Petri dishes $\left(1 \times 10^{5}\right.$ cells/piece). After low medium starving or siRNA transfecting, HBSMCs in scaffolds were transplanted into the computer-controlled bioreactor. The HBSMCs were then subjected to cyclic hydrodynamic pressure simulating bladder cycle ( $2 \mathrm{~h} /$ cycle, increasing from $0 \mathrm{~cm} \mathrm{H}_{2} \mathrm{O}$ to $10 \mathrm{~cm} \mathrm{H}_{2} \mathrm{O}$ at first $1.75 \mathrm{~h}$, then up to $100 \mathrm{~cm} \mathrm{H}_{2} \mathrm{O}, 200 \mathrm{~cm} \mathrm{H}_{2} \mathrm{O}$, or $300 \mathrm{~cm} \mathrm{H}_{2} \mathrm{O}$ rapidly and maintaining for $0.25 \mathrm{~h}$, lowering to $0 \mathrm{~cm} \mathrm{H}_{2} \mathrm{O}$ at last) for up to $24 \mathrm{~h}$. HBSMCs in the control groups were maintained under static conditions.

Semiquantitative reverse transcription-PCR and realtime PCR

Total RNAs were isolated from HBSMCs using RNAiso Plus reagent according to the manufacturer's instructions. Total RNAs were reversed transcribed using iScript cDNA Synthesis Kit and amplified by PCR using primers for each integrin as follows;

a1, forward: 5'-GGTTCCTACTTTGGCAGTATT-3', reverse: 5'-AACCTTGTCTGATTGAGAGCA-3'; $\alpha 3$, forward: 5'-AAGGGACCTTCAGGTGCA-3', reverse: 5'-TGTAGCCGGTGATTTACCAT-3'; $\alpha 4$, forward: 5'-GCTTCTCAGATCTGCTCGTG-3', reverse: 5'-GTCACTTCCAACGAGGTTTG-3'; $\alpha 5$, forward: 5'-TGCAGTGTGAGGCTGTGTACA-3', reverse: 5'-GTGGCCACCTGACGCTCT-3'; $\alpha \mathrm{V}$, forward: 5'-AATCTTCCAATTGAGGATATCAC-3', reverse: 5'-AAAACAGCCAGTAGCAACAAT-3'; $\beta 1$, forward: 5'-GAAGGGTTGCCCTCCAGA-3', reverse: 5'-GCTTGAGCTTCTCTGCTGTT-3'; $\beta 3$, forward: 5'-CCGTGACGAGATTGAGTCA-3', reverse: 5'-AGGATGGACTTTCCACTAGAA-3'.

Real time PCR was assayed with Bio-Rad iQ5 machine. Normalization of samples was achieved by measurement of the endogenous reference gene, GAPDH. All reactions were run in triplicate, and the mean value was used to calculate the ratio of target gene/GAPDH expression in each sample. 

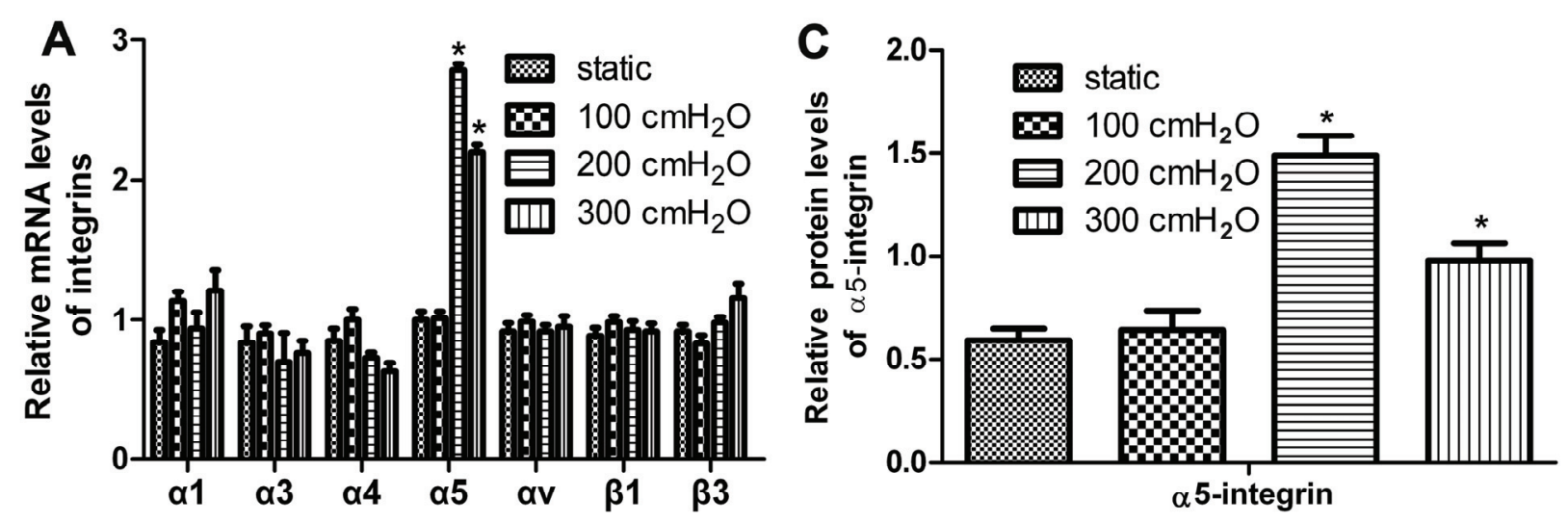

\section{B}

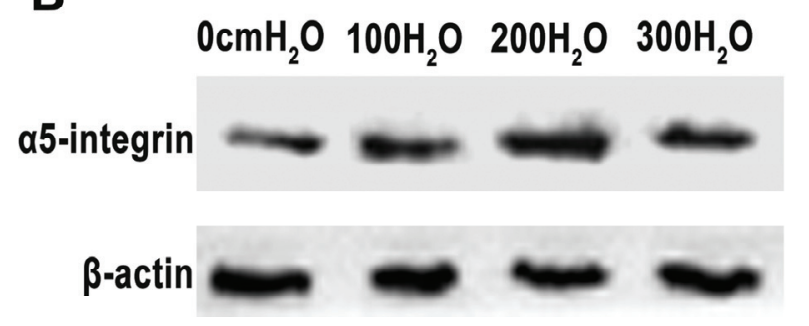

Fig. 1. Expression levels of integrin subunits under different cyclic hydrodynamic pressure groups. A: relative mRNA levels of integrin a1, a3, a4, a5, av, $\beta 1$ and $\beta 3$ subunits about HBSMCs cultured in vitro under different cyclic hydrodynamic pressure. B: representative protein bands of integrin a5 subunit and control $\beta$-actin. C: statistical graph of integrin a5. $* p<0.05$ vs. static groups

\section{Cell transfection}

A siRNA specific for integrin $\alpha 5$ (UGGCUCAGACAUUCGAUCC) siRNA was transfected by using Lipfectamine ${ }^{\mathrm{TM}} 2000$ reagent according to the manufacturer's protocol. For each transfection, Real-Time PCR was used to assess integrin $\alpha 5$ expression. The control groups were transfected by scrambled siRNA.

\section{Western blotting analysis}

HBSMCs were collected, washed twice in PBS, and lysed in RIPA buffer for $30 \mathrm{~min}$ at $4{ }^{\circ} \mathrm{C}$, and then centrifuged at $15,000 \mathrm{xg}$ for $30 \mathrm{~min}$ at $4{ }^{\circ} \mathrm{C}$. The resultant supernatant (30 $\mathrm{mg}$ protein/lane) was subjected to SDS-PAGE on $7.5 \%$ polyacrylamide gels, and the separated proteins were transferred electrophoretically onto a PVDF membrane. Western blotting analysis was performed as described previously (Tanaka et al. 1998). Membranes were incubated with specific antibodies. The antibodies used for western blotting were $\beta$-actin, integrin $\alpha 5$, p-FAK (Thr397) and FAK. The membranes were stained using an ECL kit according to the manufacturer's instructions. Protein concentrations were determined by Bradford Ultra reagent using bovine serum albumin for the standards.

\section{Cell cycle analysis by flow cytometry}

Flow cytometry was used to assess cell growth and to determine the percentage of cells in various phases of the cell cycle. After HBSMCs were treated, they were re-suspended in $1 \mathrm{ml}$ of propidium iodide (PI) staining solution $(20 \mu \mathrm{g} / \mathrm{ml}$ PI/ 10 Units/ml RNase One-Promega in $1 \mathrm{X}$ PBS) at a density of 10,000 cells $/ \mathrm{ml}$ for $20 \mathrm{~min}$ in the dark at room temperature. Then the samples were examined using an EPICS ELITE ESP flow cytometer and data was analyzed using FCS Express V2 (De Novo Software, Thornhill, Ontario, Canada). A minimum of 10,000 cells were collected in list mode files. PI histograms were used to analyze the cell cycle.

\section{Statistical analysis}

All results were expressed as means \pm standard deviation $(\mathrm{M} \pm \mathrm{SD})$. Statistical analysis was performed using Students $\mathrm{t}$ test, and $\mathrm{p}<0.05$ was considered statistically significant.

\section{Results}

Cyclic hydrodynamic pressure increased integrin a5 expression level of HBSMCs cultured in vitro

To investigate which integrin subunit in HBSMCs was changed under hydrodynamic pressure, the 
A

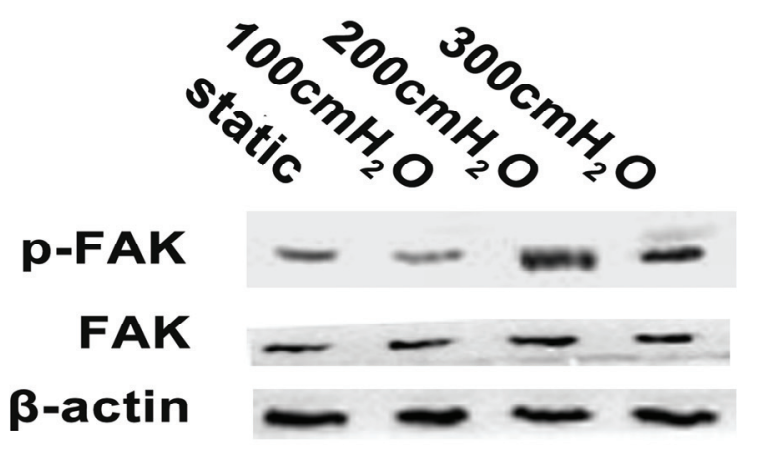

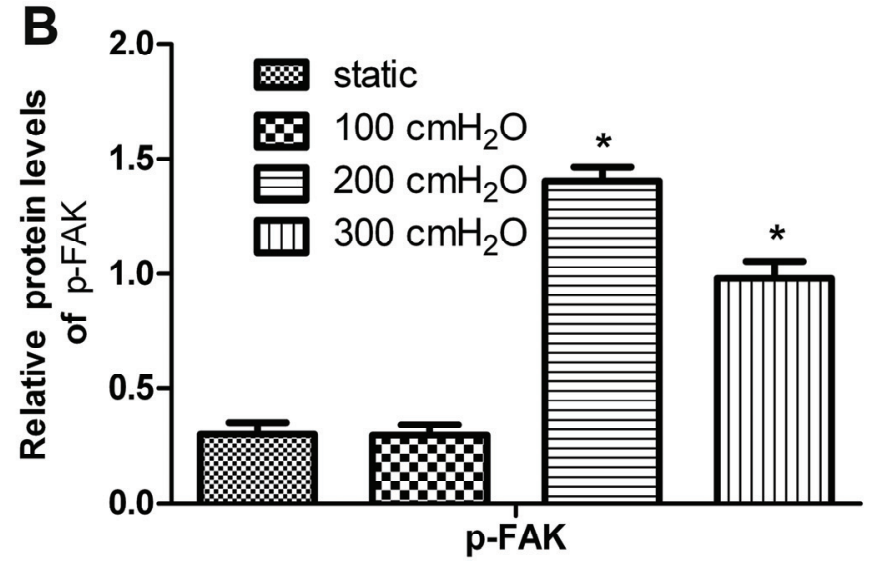

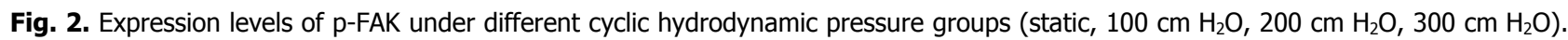
A: representative protein bands of FAK and phosphorylated FAK protein. Control (Con), a5 integrin siRNA (a5-inte siRNA). B: the data revealed levels of p-FAK under different cyclic hydrodynamic pressure groups. What the data shows are mean values $( \pm S D)$ of a representative experiment performed in triplicate. $* p<0.05$ vs. static groups
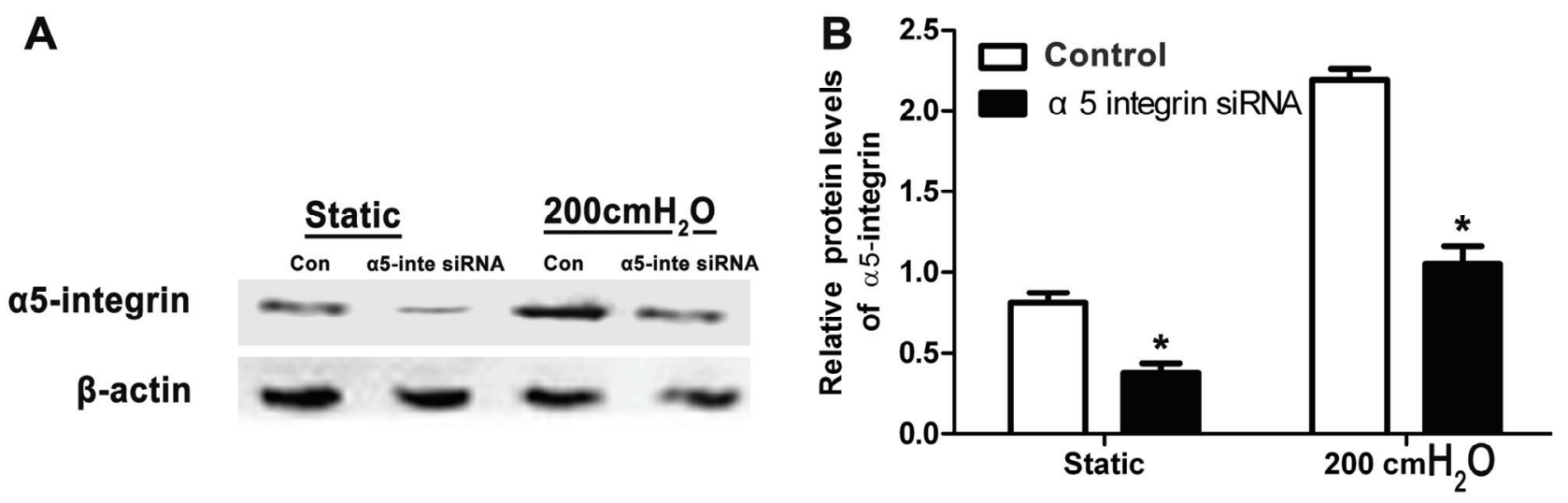

Fig. 3. Expression of integrin a5 was greatly suppressed after using integrin a5 siRNA for static groups or $200 \mathrm{~cm} \mathrm{H}_{2} \mathrm{O}$ groups. A: representative protein bands of integrin a5 protein. Control (Con), a5 integrin siRNA (a5-inte siRNA). B: after cells were transfected with siRNA specified for integrin a5 or with scrambled sequences, the data revealed that the expression of integrin a5 was greatly suppressed static groups or $200 \mathrm{~cm} \mathrm{H}_{2} \mathrm{O}$ groups. What the data shows are mean values $( \pm \mathrm{SD})$ of a representative experiment performed in triplicate. $*$ p $<0.05$ vs. control groups

genetic expression of integrin subunits $\alpha 1, \alpha 3, \alpha 4, \alpha 5, \alpha \mathrm{v}$, $\beta 1$ and $\beta 3$ were measured by RT-PCR. The data showed that only integrin $\alpha 5$ expression increased in groups of 200 and $300 \mathrm{~cm} \mathrm{H}_{2} \mathrm{O}$ groups, whereas integrin subunits $\alpha 1, \alpha 3, \alpha 4, \alpha v, \beta 1$ and $\beta 3$ were not greatly affected by cyclic hydrodynamic pressure. Compared to $0 \mathrm{~cm} \mathrm{H}_{2} \mathrm{O}$ group, the HBSMCs in 200 and $300 \mathrm{~cm} \mathrm{H}_{2} \mathrm{O}$ groups had higher integrin $\alpha 5$ expression $(\mathrm{p}<0.05)$ in (Fig. 1A). At protein level, integrin $\alpha 5$ expression significantly increased in both 200 and $300 \mathrm{~cm} \mathrm{H}_{2} \mathrm{O}$ groups with comparison to static control group $(\mathrm{p}<0.05)$, but no significant difference was found between $100 \mathrm{~cm} \mathrm{H}_{2} \mathrm{O}$ group and static control group (Fig. 1B, C).

Cyclic hydrodynamic pressure increased p-FAK (Tyr397) level of HBSMCs cultured in vitro

To identify the downstream signal molecular of integrin, the p-FAK and FAK was assessed using RTPCR. Similarly as expression of integrin $\alpha 5$, the p-FAK level significantly increased in both 200 and $300 \mathrm{~cm} \mathrm{H}_{2} \mathrm{O}$ groups $(\mathrm{p}<0.05)$, but there was no difference with $100 \mathrm{~cm} \mathrm{H}_{2} \mathrm{O}$ group compared to static control group (Fig. 2).

Integrin modulate the hydrodynamic pressure inducedproliferation of HBSMCs through the $p-F A K / F A K$ ratio

To clarify the role of integrin $\alpha 5$ and FAK signal pathway in proliferation of HBSMCs promoted by hydrodynamic pressure, the HBSMCs were treated with integrin $\alpha 5$ siRNA. $200 \quad \mathrm{~cm} \mathrm{H}_{2} \mathrm{O}$ was chosen as magnitude of pressure for this study. Compared to the scrambled siRNA control, the expression of integrin $\alpha 5$ was remarkably suppressed by target siRNA transfection in both pressure and static groups (Fig. 3), and cell 


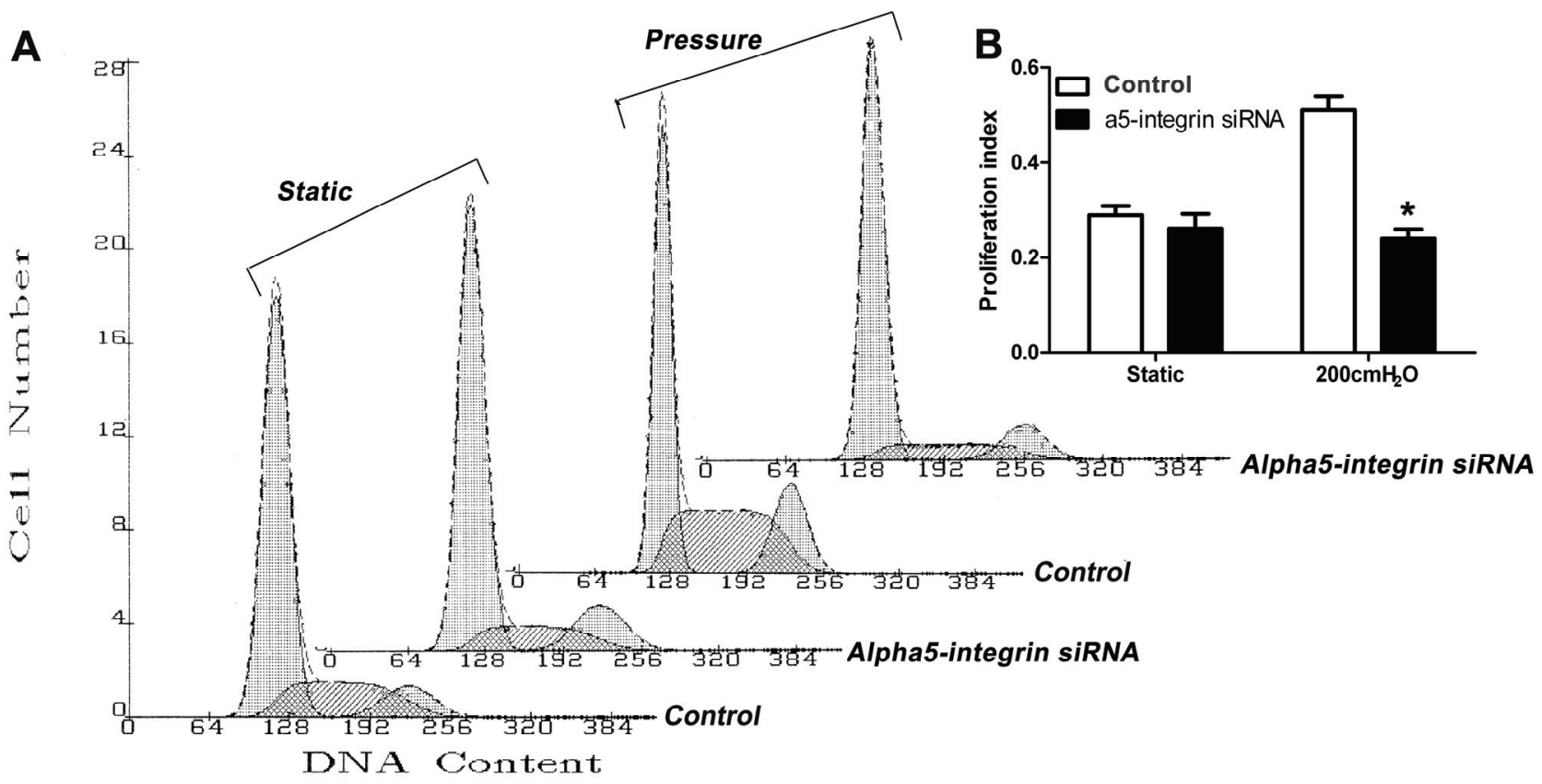

Fig. 4. Cell proliferation induced by specific cyclic hydrodynamic pressure was suppressed as expression of integrin a5 was downregulated with siRNA specific for integrin a5. A: representative flow cytometric profiles demonstrated cell cycle distribution. 3 independent assays were done and representative result was chosen. B: cell proliferation index (\%) of each group. Data were expressed as mean $\pm \mathrm{SD}$. $* \mathrm{p}<0.05$ vs. control groups

proliferation activity induced by cyclic hydrodynamic pressure was inhibited. In pressure groups, cell proliferation index decreased from $50.93 \pm 5.14 \%$ to $23.99 \pm 3.46 \%(\mathrm{p}<0.05)$; while in static groups, cell proliferation index decreased from $28.81 \pm 3.38 \%$ to $26.02 \pm 5.33 \%$ ( $p>0.05$ ) (Fig. 4).

After mRNA of integrin $\alpha 5$ was inhibited by targeted siRNA, p-FAK level was greatly abolished (Fig. 5), and the proliferation was also suppressed (Fig. 4). Compared to the scrambled siRNA control, p-FAK/FAK ratio greatly decreased $(\mathrm{p}<0.05)$ in $200 \mathrm{~cm} \mathrm{H}_{2} \mathrm{O}$ groups, but p-FAK/FAK ratio slightly dropped ( $>0.05)$ in static groups (Fig. 5). Under cyclic hydrodynamic pressure, the level of integrin $\alpha 5$, p-FAK/FAK ratio and proliferation of HBSMCs had parallel relationship with each other. That is, cyclic hydrodynamic pressure promoted proliferation of HBSMCs via integrin a5-FAK signaling transduction pathway. FAK was responsible for downstream signaling transduction of integrin $\alpha 5$.

\section{Discussion}

In relatively fixed period of time, normal urinary bladder experiences the cycle of emptying-filling. In this process, bladder smooth muscle cells undertake cyclic hydrodynamic pressure. This present study simulated the cyclic bladder physiological pressure based on the modified BOSE BioDynamic system, which applied cyclic hydrodynamic pressure simulating bladder cycle to HBSMCs cultured on scaffold. ( $2 \mathrm{~h} /$ cycle: increased from $0 \mathrm{~cm} \mathrm{H}_{2} \mathrm{O}$ to $10 \mathrm{~cm} \mathrm{H}_{2} \mathrm{O}$ at first $1.75 \mathrm{~h}$, followed by increase to $100 \mathrm{~cm} \mathrm{H}_{2} \mathrm{O}, 200 \mathrm{~cm} \mathrm{H}_{2} \mathrm{O}$, or $300 \mathrm{~cm} \mathrm{H}_{2} \mathrm{O}$ rapidly and maintained for $0.25 \mathrm{~h}$, then decreased to $0 \mathrm{~cm} \mathrm{H}_{2} \mathrm{O}$ ). These parameters used in our experiment based on our previous studies (Chen et al. 2012, Wu et al. 2012). Pressures applied to HBSMCs in this study were higher than physiological bladder pressure $\left(<40 \mathrm{~cm} \mathrm{H}_{2} \mathrm{O}\right)$ in vivo. The possible explanations are that the pressure in native bladder is dynamic not continual hydrostatic pressure during filling and voiding, and the same pressure induces weaker biological effects on cells in vitro compare to that in vivo. As the bladder detrusor experience cyclic dynamic pressure in vivo, cyclic hydrodynamic pressure is optimal to physiological condition of HBSMCs in vitro.

Integrins are a family of cell-surface receptors, which transduce mechanical signals (Chowdhury et al. 2006, Friedland et al. 2009, Shemesh et al. 2005). Integrins have numerous subunits, and different subunits have different functions. In bovine articular chondrocytes integrins $\alpha v$ and $\beta 1$ regulated dynamic compressioninduced proteoglycan synthesis (Chai et al. 2010). In VSMCs, Liu et al. (2008) found that cyclic stretch 
A

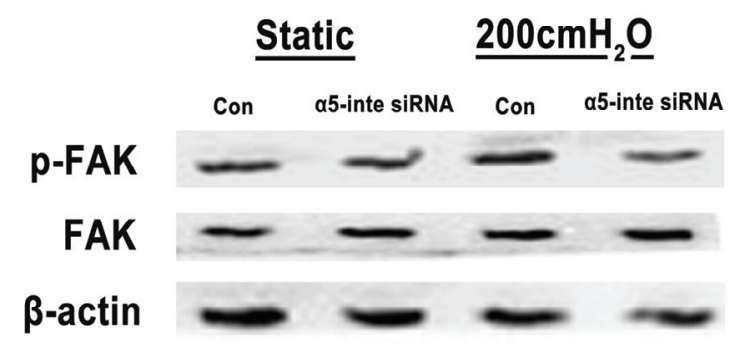

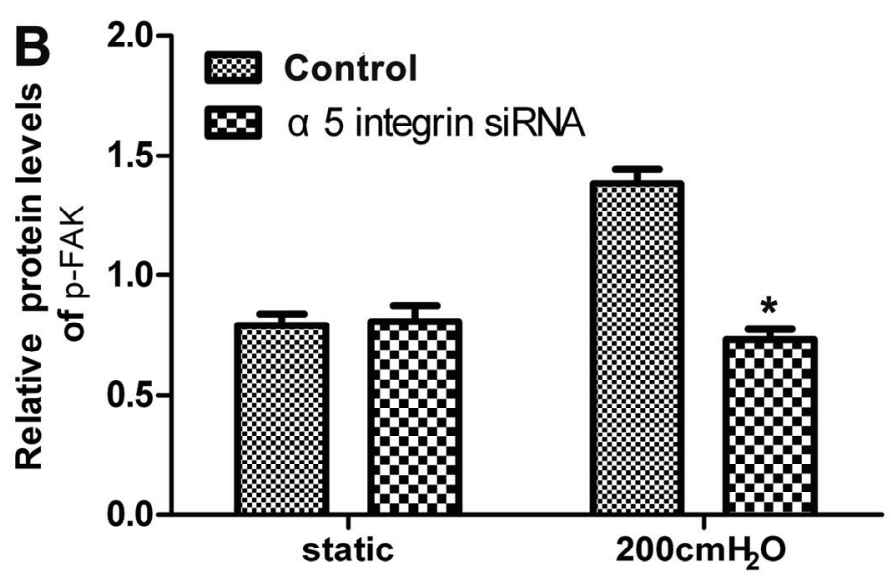

Fig. 5. Inhibition of integrin a5 resulted in declined level of $p-F A K$. A: representative protein bands of $p$-FAK protein. Control (Con), a5 integrin siRNA (a5-inte siRNA). B: statistical graph of p-FAK/FAK ratio. What the data shows are mean values ( \pm SD) of a representative experiment performed in triplicate. $* p<0.05$ vs. control groups

regulated alignment of VSMCs via integrin $\beta 1$, and Chen et al. (1999) also reported that integrin $\alpha \mathrm{V} \beta 3$ can serve as mechanosensors of shear stress to transduce mechanical stimuli into chemical signals via their association with Shc.

However, up to now, it is still a mystery to know which integrin subunit is involved in mechanotransduction in the HBSMCs. Although the previous studies showed that integrins mediate key responses to mechanical stimuli in the bladder (Upadhyay et al. 2003), it is still necessary to explore whether mechanical stimuli induce extensive or limited changes in gene expression of integrin subunits in HBSMCs. To address this question, we have examined the level of expression of integrin subunits in HBSMCs subjected to cyclic hydrodynamic pressure. The results showed that the expression of integrin $\alpha 5$ was obviously increased in groups of 200 or $300 \mathrm{~cm} \mathrm{H}_{2} \mathrm{O}$ groups, but integrin subunits $\alpha 1, \alpha 3, \alpha 4, \alpha v, \beta 1$ and $\beta 3$ were not affected under cyclic hydrodynamic pressure (Fig. 1A).

Integrins in the smooth muscle cells exhibited various biological effects, such as inducing cell growth (Upadhyay et al. 2003), proliferation (Aitken et al. 2006), etc. And our previous studies indicated that cyclic hydrodynamic pressure stimulated proliferation of HBSMCs cultured in scaffolds (Chen et al. 2012, Wu et al. 2012). These findings led us to hypothesize that integrin controls HBSMCs proliferation under hydrodynamic pressure. In order to verify this hypothesis, we found that proliferation activity of HBSMCs was greatly suppressed by down-regulating integrin $\alpha 5$ with siRNA, and the level of p-FAK has parallel relationship with integrin $\alpha 5$ under cyclic hydrodynamic pressure.
After silencing integrin $\alpha 5$ with siRNA, the ratio of p-FAK/FAK obviously declined, but not greatly changed in static groups (Fig. 5). We concluded that cyclic hydrodynamic pressure stimulated proliferation of HBSMCs cultured in scaffolds in vitro via integrin $\alpha 5$ FAK signaling pathway. FAK is a cytoplasmic tyrosine kinase identified as a key mediator of intracellular signaling by integrins (Guan 2010, Hanks and Polte 1997, Miranti and Brugge 2002). FAK has been shown to facilitate the generation of integrin-stimulated signals to downstream targets such as the ERK2 and JNK/mitogenactivated protein kinase cascades (Schlaepfer and Hunter 1998), to play a role in the regulation of cell cycle progression (Zhao et al. 2001). In this study, only one tyrosine kinase phosphorylation site (Thy397) was preliminarily examined, other tyrosine kinase phosphorylation site of FAK and its down-stream signaling molecules still need to be further explored.

The periodical hydrodynamic pressure is one of the main mechanical stimuli to HBSMCs during filling and voiding cycles in vivo. Appropriate mechanical stimuli are needed for growth and development of the urinary bladder (Haberstroh et al. 1999). In contrast, the abnormal mechanical environment created by various voiding dysfunctions, for example, the paraplegia or bladder outlet obstruction (BOO), can cause cellular alterations that can jeopardize the integrity of the bladder (Korossis et al. 2006, Stover and Nagatomi 2007). In constructing tissue engineered urinary bladder, amplification of the seeded cell is a key step. Maybe the periodical hydrodynamic pressure is to make up for the ex vivo expansion of the seeded cells. Meanwhile, the mechanism of single cyclic hydrodynamic pressure 
promoting HBSMCs proliferation may offer a new insight into some urinary bladder diseases caused by excessive mechanical forces, such as BOO studies, because previous studies about high pressures induced detrusors proliferation in BOO studies is not a single mechanical stimulus, but a complicated mechanical strains that mainly contain hydrostatic pressure and stretch force (Chang et al. 2009, Kim et al. 2005, Zhang et al. 2004). Down-regulation of integrin $\alpha 5$ could prevent the bladder hypertrophy or hyperplasia process, which was often seen under pathological conditions such as spinal cord injury and BOO.

In conclusion, we provide the first report of relationship among cyclic hydrodynamic pressure, integrins, FAK, and proliferation on HBSMCs cultured in scaffolds. The findings of this study demonstrate that integrin $\alpha 5$-FAK is a key signaling pathway in the proliferation of human bladder smooth muscle cells in response to cyclic hydrodynamic pressure, which may be used for construction of functional bladder tissue engineering and also offer a new insight into some urinary bladder diseases.

\section{Conflict of Interest}

There is no conflict of interest.

\section{Acknowledgements}

This work was supported by grants from the National Natural Science Foundation of China (No. 30872593 and 31170907), the Technology Support Program of Science and Technology Department of Sichuan Province (NO. 2010SZ0163) and the Ph.D. Programs Foundation of Ministry of Education of China (NO. 20110181110028).

\section{References}

AITKEN KJ, BLOCK G, LORENZO A, HERZ D, SABHA N, DESSOUKI O, FUNG F, SZYBOWSKA M, CRAIG L, BAGLI DJ: Mechanotransduction of extracellular signal-regulated kinases 1 and 2 mitogen-activated protein kinase activity in smooth muscle is dependent on the extracellular matrix and regulated by matrix metalloproteinases. Am J Pathol 169: 459-470, 2006.

BARCZYK M, CARRACEDO S, GULLBERG D: Integrins. Cell Tissue Res 339: 269-280, 2010.

CHANG S, HYPOLITE JA, MOHANAN S, ZDERIC SA, WEIN AJ, CHACKO S: Alteration of the PKC-mediated signaling pathway for smooth muscle contraction in obstruction-induced hypertrophy of the urinary bladder. Lab Invest 89: 823-832, 2009.

CHEN KD, LI YS, KIM M, LI S, YUAN S, CHIEN S, SHYY JY: Mechanotransduction in response to shear stress. Roles of receptor tyrosine kinases, integrins, and Shc. J Biol Chem 274: 18393-18400, 1999.

CHEN L, WEI TQ, WANG Y, ZHANG J, LI H, WANG KJ: Simulated bladder pressure stimulates human bladder smooth muscle cell proliferation via the PI3K/SGK1 signaling pathway. J Urol 188: 661-667, 2012.

CHENG J, ZHANG J, MERCHED A, ZHANG L, ZHANG P, TRUONG L, BORIEK AM, DU J: Mechanical stretch inhibits oxidized low density lipoprotein-induced apoptosis in vascular smooth muscle cells by up-regulating integrin alphavbeta3 and stablization of PINCH-1. J Biol Chem 282: 34268-34275, 2007.

CHOWDHURY TT, APPLEBY RN, SALTER DM, BADER DA, LEE DA: Integrin-mediated mechanotransduction in IL-1 beta stimulated chondrocytes. Biomech Model Mechanobiol 5: 192-201, 2006.

DAVIS GE: The development of the vasculature and its extracellular matrix: a gradual process defined by sequential cellular and matrix remodeling events. Am J Physiol 299: H245-H247, 2010.

DENG M, MOHANAN S, POLYAK E, CHACKO S: Caldesmon is necessary for maintaining the actin and intermediate filaments in cultured bladder smooth muscle cells. Cell Motil Cytoskeleton 64: 951-965, 2007.

ENGERS R, GABBERT HE: Mechanisms of tumor metastasis: cell biological aspects and clinical implications. J Cancer Res Clin Oncol 126: 682-692, 2000.

FRIEDLAND JC, LEE MH, BOETTIGER D: Mechanically activated integrin switch controls alpha5betal function. Science 323: 642-644, 2009.

GERTHOFFER WT, GUNST SJ: Invited review: focal adhesion and small heat shock proteins in the regulation of actin remodeling and contractility in smooth muscle. J Appl Physiol 91: 963-972, 2001.

GUAN JL: Integrin signaling through FAK in the regulation of mammary stem cells and breast cancer. IUBMB Life $\mathbf{6 2}$ : 268-276, 2010.

HABERSTROH KM, KAEFER M, RETIK AB, FREEMAN MR, BIZIOS R: The effects of sustained hydrostatic pressure on select bladder smooth muscle cell functions. J Urol 162: 2114-2118, 1999. 
HANKS SK, POLTE TR: Signaling through focal adhesion kinase. Bioessays 19: 137-145, 1997.

HOOD JD, CHERESH DA: Role of integrins in cell invasion and migration. Nat Rev Cancer 2: 91-100, 2002.

HYNES RO: Integrins: bidirectional, allosteric signaling machines. Cell 110: 673-687, 2002.

JACOBS CR, TEMIYASATHIT S, CASTILLO AB: Osteocyte mechanobiology and pericellular mechanics. Annu Rev Biomed Eng 12: 369-400, 2010.

KESSLER D, DETHLEFSEN S, HAASE I, PLOMANN M, HIRCHE F, KRIEG T, ECKES B: Fibroblasts in mechanically stressed collagen lattices assume a "synthetic" phenotype. J Biol Chem 276: 36575-36585, 2001.

KIM HJ, SOHNG I, KIM DH, LEE DC, HWANG CH, PARK JY, RYU JW: Investigation of early protein changes in the urinary bladder following partial bladder outlet obstruction by proteomic approach. J Korean Med Sci 20: $1000-1005,2005$.

KOITABASHI N, DANNER T, ZAIMAN AL, PINTO YM, ROWELL J, MANKOWSKI J, ZHANG D, NAKAMURA K, TAKIMOTO E, KASS DA: Pivotal role of cardiomyocyte TGF- $\beta$ signaling in the murine pathological response to sustained pressure overload. J Clin Invest 121: 2301-2312, 2011.

KOROSSIS S, BOLLAND F, INGHAM E, FISHER J, KEARNEY J, SOUTHGATE J: Review: tissue engineering of the urinary bladder: considering structure-function relationships and the role of mechanotransduction. Tissue Eng 12: 635-644, 2006.

LIU B, QU MJ, QIN KR, LI H, LI ZK, SHEN BR, JIANG ZL: Role of cyclic strain frequency in regulating the alignment of vascular smooth muscle cells in vitro. Biophys J 94: 1497-1507, 2008.

MIRANTI CK, BRUGGE JS: Sensing the environment: a historical perspective on integrin signal transduction. Nat Cell Biol 4: E83-E90, 2002.

PYLE AL, ATKINSON JB, POZZI A, REESE J, ECKES B, DAVIDSON JM, CRIMMINS DL, YOUNG PP: Regulation of the atheroma-enriched protein, SPRR3, in vascular smooth muscle cells through cyclic strain is dependent on integrin alpha1 beta1/collagen interaction. Am J Pathol 173: 1577-1588, 2008.

SCHLAEPFER DD, HUNTER T: Integrin signalling and tyrosine phosphorylation: just the FAKs? Trends Cell Biol 8 : 151-157, 1998.

SHEMESH T, GEIGER B, BERSHADSKY AD, KOZLOV MM: Focal adhesions as mechanosensors: a physical mechanism. Proc Natl Acad Sci US A 102: 12383-12388, 2005.

SHI ZD, TARBELL JM: Fluid flow mechanotransduction in vascular smooth muscle cells and fibroblasts. Ann Biomed Eng 39: 1608-1619, 2011.

STOVER J, NAGATOMI J: Cyclic pressure stimulates DNA synthesis through the PI3K/Akt signaling pathway in rat bladder smooth muscle cells. Ann Biomed Eng 35: 1585-1594, 2007.

TANAKA S, NEMOTO K, YAMAMURA E, ICHIKAWA A: Intracellular localization of the 74- and 53-kDa forms of L-histidine decarboxylase in a rat basophilic/mast cell line, RBL-2H3. J Biol Chem 273: 8177-8182, 1998.

UPADHYAY J, AITKEN KJ, DAMDAR C, BOLDUC S, BAGLI DJ: Integrins expressed with bladder extracellular matrix after stretch injury in vivo mediate bladder smooth muscle cell growth in vitro. $J$ Urol 169: 750-755, 2003.

WILSON E, SUDHIR K, IVES HE: Mechanical strain of rat vascular smooth muscle cells is sensed by specific extracellular matrix/integrin interactions. J Clin Invest 96: 2364-2372, 1995.

WU T, CHEN L, WEI T, WANG Y, XU F, WANG K: Effect of cyclic hydrodynamic pressure-induced proliferation of human bladder smooth muscle through Ras-related C3 botulinum toxin substrate 1, mitogen-activated protein kinase kinase 1/2 and extracellular regulated protein kinases 1/2. Int J Urol 19: 867-874, 2012.

ZHANG EY, STEIN R, CHANG S, ZHENG Y, ZDERIC SA, WEIN AJ, CHACKO S: Smooth muscle hypertrophy following partial bladder outlet obstruction is associated with overexpression of non-muscle caldesmon. Am J Pathol 164: 601-612, 2004.

ZHAO J, PESTELL R, GUAN JL: Transcriptional activation of cyclin D1 promoter by FAK contributes to cell cycle progression. Mol Biol Cell 12: 4066-4077, 2001.

ZHOU D, HERRICK DJ, ROSENBLOOM J, CHAQOUR B: Cyr61 mediates the expression of VEGF, alphav-integrin, and alpha-actin genes through cytoskeletally based mechanotransduction mechanisms in bladder smooth muscle cells. J Appl Physiol 98: 2344-2354, 2005. 